\title{
BMJ
}

\section{Steroids and bronchodilators for acute bronchiolitis in the first two years of life: systematic review and meta-analysis}

\author{
Lisa Hartling, assistant professor, ${ }^{1}$ Ricardo M Fernandes, PhD student, ${ }^{2}$ Liza Bialy, project coordinator, ${ }^{1}$ \\ Andrea Milne, research assistant, ${ }^{1}$ David Johnson, professor, ${ }^{3}$ Amy Plint, associate professor, ${ }^{4}$ Terry P \\ Klassen, professor, ${ }^{5}$ Ben Vandermeer, biostatistician 1
}

${ }^{1}$ Alberta Research Centre for Health Evidence, Department of

Pediatrics, University of Alberta, 11402 University Avenue, Edmonton, AB, Canada T6G 2J3

${ }^{2}$ Gulbenkian Program for Advanced Medical Education: Child and Family Department, Hospital de Santa Maria; Clinical Pharmacology and Therapeutics, Institute of Molecular Medicine, Lisbon, Portugal

${ }^{3}$ Department of Pediatrics and Department of Physiology and Pharmacology, University of Calgary and Alberta Children's Hospital, Calgary, AB, Canada

${ }^{4}$ Department of Pediatrics and Department of Emergency Medicine, University of Ottawa, Ottawa, ON, Canada

${ }^{5}$ Manitoba Institute of Child Health, Department of Pediatrics and Child Health, University of Manitoba, Winnipeg, MB, Canada Correspondence to: L Hartling hartling@ualberta.ca

Cite this as: BMJ 2011;342:d1714 doi:10.1136/bmi.d1714

\section{ABSTRACT}

Objective To evaluate and compare the efficacy and safety of bronchodilators and steroids, alone or combined, for the acute management of bronchiolitis in children aged less than 2 years.

Design Systematic review and meta-analysis.

Data sources Medline, Embase, Central, Scopus, PubMed, LILACS, IranMedEx, conference proceedings, and trial registers.

Inclusion criteria Randomised controlled trials of children aged 24 months or less with a first episode of bronchiolitis with wheezing comparing any bronchodilator or steroid, alone or combined, with placebo or another intervention (other bronchodilator, other steroid, standard care).

Review methods Two reviewers assessed studies for inclusion and risk of bias and extracted data. Primary outcomes were selected by clinicians a priori based on clinical relevance: rate of admission for outpatients (day 1 and up to day 7) and length of stay for inpatients. Direct meta-analyses were carried out using random effects models. A mixed treatment comparison using a Bayesian network model was used to compare all interventions simultaneously.

Results 48 trials (4897 patients, 13 comparisons) were included. Risk of bias was low in $17 \%(n=8)$, unclear in $52 \%(n=25)$, and high in 31\% $(n=15)$. Only adrenaline (epinephrine) reduced admissions on day 1 (compared with placebo: pooled risk ratio $0.67,95 \%$ confidence interval 0.50 to 0.89 ; number needed to treat $15,95 \%$ confidence interval 10 to 45 for a baseline risk of $20 \%$; 920 patients). Unadjusted results from a single large trial with low risk of bias showed that combined dexamethasone and adrenaline reduced admissions on day 7 (risk ratio 0.65, 0.44 to 0.95 ; number needed to treat 11,7 to 76 for a baseline risk of $26 \%$; 400 patients). A mixed treatment comparison supported adrenaline alone or combined with steroids as the preferred treatments for outpatients (probability of being the best treatment based on admissions at day 1 were $45 \%$ and $39 \%$, respectively). The incidence of reported harms did not differ. None of the interventions examined showed clear efficacy for length of stay among inpatients.
Conclusions Evidence shows the effectiveness and superiority of adrenaline for outcomes of most clinical relevance among outpatients with acute bronchiolitis, and evidence from a single precise trial for combined adrenaline and dexamethasone.

\section{INTRODUCTION}

Bronchiolitis is the most common disease of the lower respiratory tract during the first year of life. ${ }^{1}$ Respiratory syncytial virus is the underlying cause of most bronchiolitis and this infection is associated with substantial morbidity in young children. ${ }^{23}$ Ongoing research in bronchiolitis reflects both the burden of disease in developed and developing countries and a lack of clear evidence for its therapeutic management. ${ }^{45}$ Previous studies have shown substantial variation in the management of acute bronchiolitis throughout the world, including the use of different bronchodilators ( $\beta_{2}$ agonists, adrenaline (epinephrine), anticholinergics) and steroids. ${ }^{6-9}$ Some of this variation may be attributable to varying severity of disease or to different care settings and geographical location.

Several systematic reviews have assessed various treatments, including $\beta_{2}$ agonists and anticholinergics, adrenaline, corticosteroids, hypertonic saline, antibiotics, surfactant, ribavirin, and chest physiotherapy. ${ }^{10}$ These reviews have failed to provide convincing evidence to support any of these treatments in the acute management of bronchiolitis, and their routine use is not recommended by current clinical practice guidelines. ${ }^{11-13}$ Despite implementation of these guidelines, bronchodilators especially are still frequently used. ${ }^{1415}$

A 2003 report recommended rigorously designed, adequately sized randomised controlled trials on treatments that showed some potential for being efficacious, including nebulised bronchodilators (adrenaline, salbutamol, or ipratropium bromide, alone or combined), oral or parenteral corticosteroids (preferentially dexamethasone), and inhaled corticosteroids (especially budesonide). ${ }^{4}$ Two large trials examining some of these interventions have recently been completed. The largest trial ever published in this area, concerning 800 children in Canada, used a factorial design 


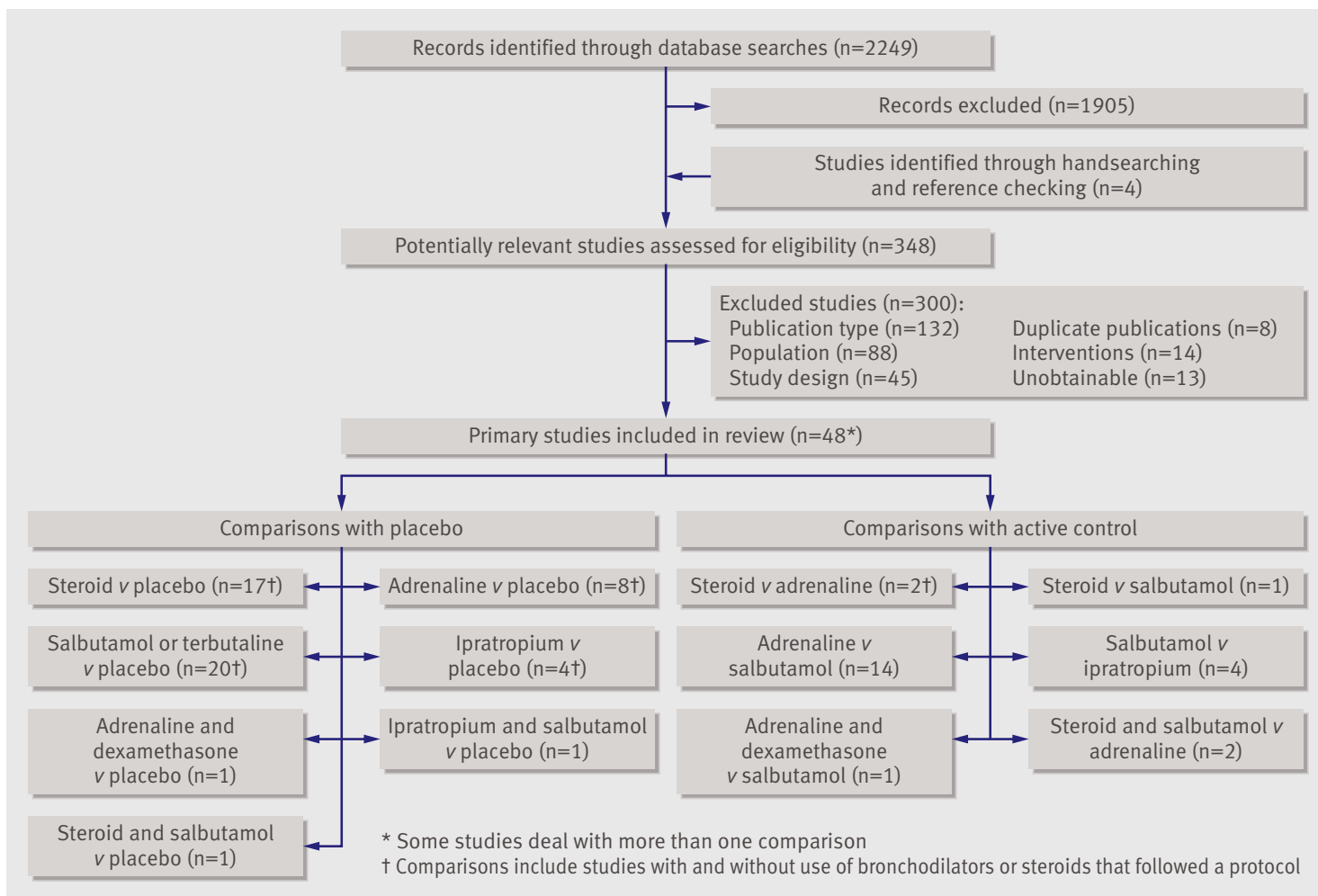

Fig 1| Flow diagram for study selection

to examine adrenaline and dexamethasone, alone or combined, compared with placebo. ${ }^{16}$ Another trial completed concurrently in the United States compared dexamethasone with placebo in a sample of 600 children. ${ }^{17}$ These two large trials add substantially to the evidence and provide a strong signal for further synthesis work. ${ }^{18}$

These recent trials also raise new questions and potentially novel approaches to the acute management of bronchiolitis that warrant closer investigation. Specifically, one trial showed a $35 \%$ relative reduction on rates of admission to hospital with combined adrenaline and dexamethasone treatment compared with placebo. ${ }^{16}$ Previously, a smaller trial was the first to show the effectiveness of oral dexamethasone in reducing hospital admissions in outpatients with acute bronchiolitis. ${ }^{19}$ The unique feature of this trial, among others that did not show effectiveness, was that high dose steroids were administered along with a bronchodilator (salbutamol) according to a defined protocol rather than at the discretion of the attending physician. Although the interactive effect of steroids and bronchodilators has emerged as a potential treatment option, ${ }^{16}$ it has not been examined at the level of systematic review and placed in the context of other evidence.

Driven by recent evidence and current uncertainties in practice, we systematically evaluated and compared the efficacy and safety of bronchodilators $\left(\beta_{2}\right.$ agonists, adrenaline, anticholinergics) and steroids, alone or combined, for the acute management of bronchiolitis. We also determined the effectiveness of steroids with a fixed protocol for bronchodilator use compared with those in which the bronchodilator was given at the discretion of the attending physician, and bronchodilators given with and without steroids. By carrying out mixed treatment comparisons, we sought to improve on previous systematic reviews that focused primarily on pairwise, direct comparisons, often with the comparator being a placebo. Mixed treatment analysis is a relatively new development in the area of evidence synthesis, with the advantage of combining data on different interventions for the same condition. ${ }^{2021}$

\section{METHODS}

Through all stages of this work, we followed a protocol that was developed by the coauthors before the review began, in which all outcomes and analyses were specified a priori.

\section{Search strategy}

A medical research librarian searched Medline Ovid version (1950 to November week 2, 2009), Embase Ovid version (1980 to 2009 week 47), EBM Reviews - Cochrane Central Register of Controlled Trials (4th quarter 2009), LILACS-Latin American and Caribbean Center on Health Sciences Information (25 November 2009), PubMed (9 March 2009), Scopus (1823 to 25 November 2009), and IranMedEx (26 November 2009). (See web extra appendix A for the search strings.) We applied no restrictions on year or language. To identify unpublished studies and studies in progress, we searched conference proceedings for 
Table 1| Overview of studies included in systematic review

\begin{tabular}{|c|c|c|c|c|c|}
\hline Comparison by population & $\begin{array}{l}\text { No of studies } \\
\text { (No of patients) }\end{array}$ & $\begin{array}{c}\text { No of studies } \\
\text { providing data } \\
\text { for primary outcome }\end{array}$ & $\begin{array}{l}\text { Years of publication } \\
\text { (median) }\end{array}$ & Countries of study & Risk of bias \\
\hline \multicolumn{6}{|l|}{ Steroid $v$ placebo: } \\
\hline Inpatients & $9(772)$ & 8 & 1996-2007 (2000) & $\begin{array}{l}\text { UK (2), Israel, Belgium, Mexico, Canada, } \\
\text { Thailand, Brazil, USA }\end{array}$ & 1 low, 4 unclear, 4 high \\
\hline Outpatients & 8 (1778) & 8 & $1998-2009(2002 / 2004)$ & $\begin{array}{l}\text { USA (2), Canada (2), Turkey (2), Israel, } \\
\text { Paraguay }\end{array}$ & 1 low, 4 unclear, 3 high \\
\hline \multicolumn{6}{|l|}{ Adrenaline $v$ placebo: } \\
\hline Inpatients & $3(330)$ & 2 & $2002-3(2002)$ & England, Canada, Australia & 1 low, 1 unclear, 1 high \\
\hline Outpatients & $5(526)$ & 4 & $1995-2009$ (2005) & Turkey (2), Iran, Canada, USA & 2 low, 2 unclear, 1 high \\
\hline \multicolumn{6}{|c|}{ Salbutamol* or terbutaline $v$ placebo: } \\
\hline Inpatients: & $9(488)$ & 6 & 1991-2009 (1997) & $\begin{array}{l}\text { Turkey (2), France, Saudi Arabia, Singapore, } \\
\text { Canada, USA, Tunisia, Australia }\end{array}$ & 1 low, 5 unclear, 3 high \\
\hline Outpatients & $11(926)$ & 6 & 1990-2008 (1998) & $\begin{array}{l}\text { Canada (3), Turkey (3), USA (2), Egypt, India, } \\
\text { Iran }\end{array}$ & 2 low, 6 unclear, 3 high \\
\hline \multicolumn{6}{|l|}{ Ipratropium v placebo: } \\
\hline Inpatients & $3(194)$ & 2 & 1995-2008 (1997) & Saudi Arabia, Singapore, Turkey & 3 unclear \\
\hline Outpatients & $1(72)$ & 1 & 1992 & Canada & 1 unclear \\
\hline \multicolumn{6}{|c|}{ Adrenaline and dexamethasone $v$ other: } \\
\hline Inpatients & 0 & NA & NA & NA & NA \\
\hline Outpatients & $2(436)$ & 2 & 2004, 2009 & Turkey, Canada & 1 low, 1 high \\
\hline \multicolumn{6}{|c|}{ Ipratropium and salbutamol* $v$ placebo: } \\
\hline Inpatients & 0 & NA & NA & NA & NA \\
\hline Outpatients & $1(72)$ & 1 & 1992 & Canada & 1 unclear \\
\hline \multicolumn{6}{|l|}{ Steroid $v$ adrenaline: } \\
\hline Inpatients & 0 & NA & NA & NA & NA \\
\hline Outpatients & $2(444)$ & 2 & 1995,2009 & Turkey, Canada & 1 low, 1 high \\
\hline \multicolumn{6}{|l|}{ Adrenaline $v$ salbutamol*: } \\
\hline Inpatients & $6(433)$ & 4 & 1993-2007 (2001/2002) & Canada (2), Jordan, Chile, Iran, India & 1 low, 3 unclear, 2 high \\
\hline Outpatients & $8(378)$ & 6 & $1995-2007(2004)$ & Turkey (3), USA (2), Israel, Iran, Canada, & 4 low, 3 unclear, 1 high \\
\hline \multicolumn{6}{|l|}{ Steroid $v$ salbutamol*: } \\
\hline Inpatients & 0 & NA & NA & NA & NA \\
\hline Outpatients & $1(45)$ & 1 & 1995 & Turkey & 1 high \\
\hline \multicolumn{6}{|l|}{ Salbutamol $v$ ipratropium: } \\
\hline Inpatients & $4(192)$ & 3 & $1995-2008(2000)$ & Saudi Arabia, Singapore, Turkey (2) & 3 unclear, 1 high \\
\hline Outpatients & 0 & NA & NA & NA & NA \\
\hline \multicolumn{6}{|c|}{ Steroid and salbutamo ${ }^{\star} v$ other: } \\
\hline Inpatients & 0 & NA & NA & NA & NA \\
\hline Outpatients & $2(103)$ & 2 & 1998, 2004 & Turkey (2) & 2 high \\
\hline
\end{tabular}

NA=Not applicable.

*Salbutamol has been used throughout to also refer to albuterol.

six relevant organisations and six clinical trials registers (see web extra appendix A). Finally, we checked reference lists of relevant studies and previous reviews and contacted experts in the specialty.

\section{Study selection}

Studies were included if they were randomised controlled trials, involved inpatients or outpatients aged 24 months or less with bronchiolitis, and compared a bronchodilator (salbutamol or terbutaline, adrenaline, ipratropium bromide) or steroid (inhaled or systemic), or both combined, with another intervention (either placebo or another intervention including another bronchodilator or steroid). Bronchiolitis was defined as a physician diagnosed first episode of acute wheezing with respiratory distress and associated with clinical evidence of viral infection. We excluded studies in which any participants had a history of wheezing, respiratory distress, or a formal diagnosis of asthma. We chose to focus on first episodes of wheezing to deal with the possible overlap between bronchiolitis, recurrent wheezing, and asthma. We also excluded studies in the intensive care setting or with intubated or ventilated participants, and studies assessing longer courses of steroids started during the acute phase of bronchiolitis for the prevention of postbronchiolitic wheezing. The primary outcomes, selected by the clinician authors a priori based on clinical relevance, were rate of admissions at day 1 and day 7 for outpatient studies and length of stay in hospital for inpatient studies. Secondary outcomes included change in clinical score, oxygen saturation, respiratory 


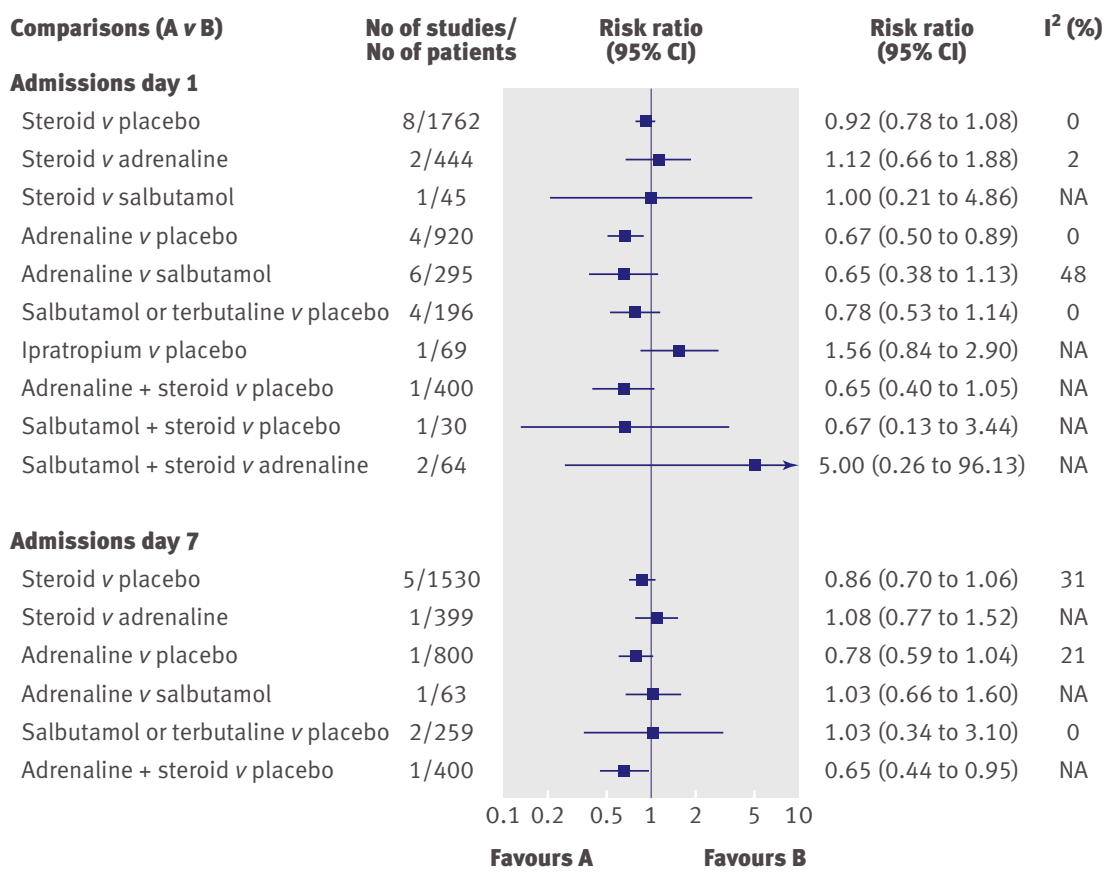

Fig 2 | Results from meta-analysis of direct comparisons for admission rates from emergency department (day 1 and day 7) in outpatients. Only comparisons with quantitative results are shown rate, and heart rate; readmissions (for inpatients); return visits to the emergency department or any healthcare provider; and harms or adverse events.

Two reviewers independently screened the titles and abstracts to determine if an article met the inclusion criteria. The full text of studies classified as "relevant" or "unclear" were assessed independently by two reviewers using a standard form. Disagreements were resolved by consensus or adjudication by a third party.

\section{Risk of bias assessment}

Included studies were assessed using the Cochrane Collaboration risk of bias tool. ${ }^{22}$ The tool consists of six domains (sequence generation, allocation

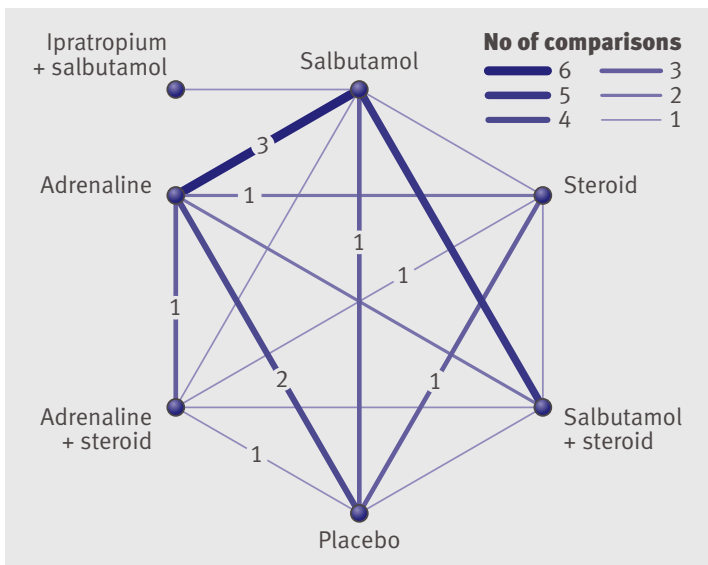

Fig 3| Comparisons (14 studies) contributing to mixed treatment analysis for admissions at day 1 . Numerals within figure are studies at low risk of bias (four in total) concealment, blinding, incomplete outcome data, selective outcome reporting, and "other sources of bias"). Blinding and incomplete outcome data were assessed separately for the following types of outcomes: administrative, clinical or respiratory scores and other clinical variables, and others (for example, adverse events).

Two reviewers independently assessed risk of bias of included studies. One reviewer assessed reports written in Turkish. Discrepancies were resolved by consensus among three reviewers.

\section{Data extraction}

Data were extracted using a standardised form (available from authors) and entered into Microsoft Excel (Microsoft, Redmond, WA). One reviewer extracted data and a second reviewer checked these for accuracy and completeness. Extracted data included study characteristics, inclusion and exclusion criteria, characteristics of participants, interventions (including the use of a fixed protocol for cointerventions), outcomes, and results. Reviewers resolved discrepancies by consensus or in consultation with a third party. All quantitative data were checked by the statistician during analysis.

\section{Grading the body of evidence}

Two reviewers independently graded the quality of the body of evidence for the comparisons deemed most clinically relevant. Assessments, based on a modified GRADE approach, were completed for length of stay and admissions, change in clinical score, and adverse events. ${ }^{2324}$ Domains examined were risk of bias, consistency, directness, and precision. Decision rules were developed a priori based on clinical and methodological relevance and are available on request. Discrepancies were resolved through discussion. The overall strength of evidence was graded as high, moderate, low, or insufficient (see web extra appendix B).

\section{Statistical analysis}

We considered studies of inpatients and outpatients separately, except for harms related data. Weighted mean differences were used to pool continuous variables when the same measurement scale was used (for example, heart rate) and standardised mean differences when different scales were used (for example, clinical scores). For pairwise meta-analysis, we used risk ratios to pool dichotomous variables. Data were combined using the DerSimonian-Laird random effects models ${ }^{25}$ in Review Manager version 5.0 (Cochrane Collaboration, Copenhagen, Denmark). Results are reported with 95\% confidence intervals, and statistical significance was set at $\mathrm{P}<0.05$. Statistical heterogeneity was quantified using the $\mathrm{I}^{2}$ statistic. A value greater than $50 \%$ was considered to be substantial heterogeneity. ${ }^{2627} \mathrm{We}$ calculated numbers needed to treat using the final risk ratios and the simple average baseline risk across all included trials - that is, the number of events divided by the number of participants 
Table $2 \mid$ Results of direct comparisons for change in clinical score among outpatients

\begin{tabular}{|c|c|c|c|c|}
\hline Comparison & Time point & $\begin{array}{l}\text { No of studies } \\
\text { (No of patients) }\end{array}$ & $\begin{array}{l}\text { Standardised mean } \\
\text { difference }(95 \% \mathrm{Cl})\end{array}$ & $I^{2}(\%)$ \\
\hline \multirow{5}{*}{ Steroid $v$ placebo } & 1 hour & $4(1006)$ & $-0.04(-0.16$ to 0.09$)$ & 0 \\
\hline & 2 hour & $3(214)$ & $-0.17(-0.55$ to 0.21$)$ & 43 \\
\hline & 3-6 hours & $4(808)$ & $-0.14(-0.50$ to 0.21$)$ & 68 \\
\hline & $12-24$ hours & $1(69)$ & $0.13(-0.51$ to 0.76$)$ & 36 \\
\hline & 3-10 days & $4(224)$ & $-0.20(-0.61$ to 0.21$)$ & 55 \\
\hline \multirow{3}{*}{ Steroid $v$ adrenaline } & 1 hour & $2(442)$ & $0.31(0.12 \text { to } 0.50)^{\star}$ & 0 \\
\hline & 2 hours & $1(45)$ & $0.35(-0.27$ to 0.98$)$ & NA \\
\hline & 3-6 hours & $1(45)$ & $0.42(-0.20$ to 1.05$)$ & NA \\
\hline \multirow{3}{*}{ Steroid $v$ salbutamol } & 1 hour & $1(45)$ & $0.65(0.01$ to 1.28$) \dagger$ & NA \\
\hline & 2 hours & $1(45)$ & $0.36(-0.27$ to 0.98$)$ & NA \\
\hline & 3-6 hours & $1(45)$ & $0.70(0.06$ to 1.34$) \dagger$ & NA \\
\hline \multirow{2}{*}{ Adrenaline $v$ placebo } & 1 hour & $4(900)$ & $-0.45(-0.66 \text { to }-0.23)^{\star}$ & 40 \\
\hline & 2 hours & $1(30)$ & $-0.83(-1.58 \text { to }-0.08)^{\star}$ & NA \\
\hline \multirow{4}{*}{ Adrenaline $v$ salbutamol } & 1 hour & $6(248)$ & $-0.11(-0.36$ to 0.14$)$ & 0 \\
\hline & 2 hours & $4(207)$ & $-0.09(-0.37$ to 0.18$)$ & 0 \\
\hline & $12-24$ hours & $1(69)$ & $-0.21(-0.86$ to 0.44$)$ & 41 \\
\hline & 3-10 days & $1(69)$ & $-0.50(-0.98 \text { to }-0.02)^{\star}$ & 0 \\
\hline \multirow{3}{*}{ Salbutamol $v$ placebo } & 1 hour & $8(565)$ & $-0.49(-0.96$ to -0.01$) \dagger$ & 86 \\
\hline & 2 hours & $2(100)$ & $-0.04(-1.07$ to 0.99$)$ & 84 \\
\hline & 3-6 hours & $1(60)$ & $-0.79(-2.53$ to 0.95$)$ & 90 \\
\hline Ipratropium $v$ placebo & 2 hours & $1(69)$ & $-0.14(-0.61$ to 0.33$)$ & NA \\
\hline $\begin{array}{l}\text { Adrenaline and dexamethasone } \\
v \text { placebo }\end{array}$ & 1 hour & $1(399)$ & $-0.34(-0.54$ to -0.14$) \ddagger$ & NA \\
\hline \multirow{3}{*}{$\begin{array}{l}\text { Adrenaline and dexamethasone } \\
v \text { salbutamol }\end{array}$} & 2 hours & $1(35)$ & $-0.17(-0.87$ to 0.52$)$ & NA \\
\hline & $12-24$ hours & $1(35)$ & $0.00(-0.70$ to 0.70$)$ & NA \\
\hline & 3-10 days & $1(35)$ & $-1.22(-1.98$ to -0.46$) \ddagger$ & NA \\
\hline \multirow{3}{*}{$\begin{array}{l}\text { Steroid and salbutamol } \\
v \text { placebo }\end{array}$} & 1 hour & $1(30)$ & $-0.34(-1.75$ to 1.07$)$ & NA \\
\hline & 2 hours & $1(30)$ & $-0.67(-2.04$ to 0.70$)$ & NA \\
\hline & 3-6 hours & $1(30)$ & $-1.08(-2.43$ to 0.27$)$ & NA \\
\hline \multirow{4}{*}{$\begin{array}{l}\text { Steroid and salbutamol } \\
v \text { adrenaline }\end{array}$} & 1 hour & $1(30)$ & $0.36(-0.36$ to 1.08$)$ & NA \\
\hline & 2 hours & $2(64)$ & $0.25(-0.26$ to 0.77$)$ & 0 \\
\hline & $12-24$ hours & $1(34)$ & $0.30(-0.43$ to 1.02$)$ & NA \\
\hline & 3-10 days & $1(34)$ & $-0.16(-0.88$ to 0.56$)$ & NA \\
\hline
\end{tabular}

NA=not applicable.

*Results favour adrenaline.

tResults favour salbutamol.

$\ddagger$ Results favour combined adrenaline and dexamethasone.

across the placebo arms of relevant studies. We also computed numbers needed to treat using the minimum and maximum baseline risk for the trials included in the meta-analysis. In our main analysis, for studies where groups received combined interventions that followed a protocol, we considered the common intervention across groups to "cancel out." For example, to obtain an overall main effect we considered a study comparing combined steroid and bronchodilator with bronchodilator alone in the comparison of steroid with placebo. Furthermore, two groups from factorial trials could contribute to the same analysis - for example, combined steroid and placebo compared with combined placebo and placebo, and combined steroid and bronchodilator compared with combined bronchodilator and placebo would both contribute to the comparison of steroid with placebo. The robustness of this assumption was tested by carrying out subgroup analyses comparing results in trials with cointerventions following a protocol versus trials with cointerventions at the discretion of the physician to explore potential additive (synergistic) or subtractive (antagonistic) effects. A priori we planned to do sensitivity analyses based on risk of bias (low $v$ unclear or high).

For the primary outcomes we carried out a mixed treatment analysis using a Bayesian network model to compare all interventions simultaneously and to use all available information on treatment effects in a single analysis. ${ }^{212829}$ Mean differences or log odds ratios were modelled using non-informative prior distributions. A normal prior distribution with mean 0 and large variance $(10000)$ was used for each of the trial means or $\log$ odds ratios, whereas their between study variance had a uniform prior with range 0 to 2 (admissions) or 0 to 10 (length of stay). These priors were checked for influence with sensitivity analyses. We carried out Markov Chain Monte Carlo simulations using WinBugs software to obtain simultaneous estimates of all interventions compared with placebo as well as estimates of which interventions were the best. ${ }^{30}$ A burn-in sample of 20000 iterations was followed by 200000 iterations used to compute estimates. Results are reported with $95 \%$ credibility intervals. We considered all trial groups separately in the analysis. For example, a trial comparing steroid with placebo using a fixed protocol for bronchodilator use in both arms would contribute two arms to the mixed treatment analysis: combined steroid and bronchodilator and bronchodilator. Factorial trials contributed all four groups, and correlation between groups in such trials was factored into the computations. We checked the analyses for consistency using cross validation of all contrasts that had direct evidence. ${ }^{31}$

\section{RESULTS}

Figure 1 shows the flow of studies through the selection process. Forty eight studies totalling 4897 patients were included (see web extra appendix C). Table 1 shows the comparisons made, the number of studies for each comparison by inpatient and outpatient population, the number of studies that provided data for our primary outcomes, the years of publication, and country of study. The drugs were administered in a variety of ways and varied across studies and interventions: corticosteroids -systemic (oral, intravenous, or intramuscular) or nebulised; adrenaline -nebulised; and bronchodilators -mostly nebulised. The risk of bias was low for eight studies (17\%), unclear for $25(52 \%)$, and high for 15 (31\%). Twenty four studies only included infants aged less than 1 year.

\section{Outpatients}

Figure 2 displays the effect estimates for the primary outcome of admission rates from the emergency department (day 1) for the different direct comparisons. The results were statistically significant for only one comparison, showing a reduction of 33\% for adrenaline compared with placebo (pooled risk ratio 0.67 , 


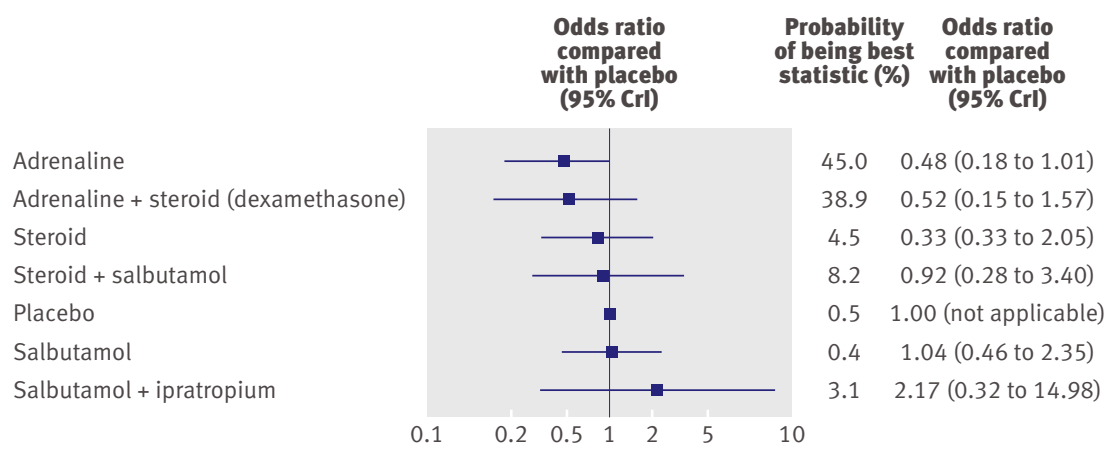

Fig $4 \mid$ Results of mixed treatment analysis for admissions at day 1, showing probability ranking and probability of being best statistic

$95 \%$ confidence interval 0.50 to 0.89 ). The strength of evidence for this finding was considered moderate owing to lack of precision (see web extra appendix B). The number needed to treat based on the average baseline risk of admission from all studies $(20 \%)$ was 15 (95\% confidence interval 10 to 45$)$. The number needed to treat ranged from 4 (95\% confidence interval 3 to 12 , baseline risk $75 \%$ ) to 20 (13 to 59 , baseline risk $15 \%)$. The results were sensitive to risk of bias: when studies with an unclear risk of bias were removed, the pooled estimate for the two studies $(n=842)$ at low risk of bias was no longer statistically significant (pooled risk ratio $0.77,0.56$ to 1.07 ). Subgroup analyses showed non-statistically significant differences between studies combining adrenaline with steroids that followed a protocol (pooled risk ratio $0.74,0.45$ to 1.23 ; one study, $\mathrm{n}=400$ ) compared with those that did not follow a protocol $(0.62,0.40$ to 0.94 ; four studies, $\mathrm{n}=520$; ratio of risk ratios $1.19,0.61$ to 2.33 ). An effect of a similar magnitude was shown with combined adrenaline and dexamethasone compared with placebo (35\%), but this did not reach significance $(\mathrm{P}=0.07)$ (pooled risk ratio $0.65,0.4$ to 1.05 ; one study, $\mathrm{n}=400)$.

Figure 3 illustrates the comparisons and number of studies for each that were examined in the mixed treatment comparison for admissions at day 1. Cross validation showed that the results from the mixed treatment analysis were consistent with direct evidence not differing significantly from indirect evidence for any of the paired comparisons where direct evidence was available. The mixed treatment comparison identified adrenaline alone and combined adrenaline and dexamethasone as the interventions with the highest probability of being most effective, with about half the odds of being admitted from the emergency department compared with placebo (fig 4 ). The odds ratios were 0.48 (95\% credibility interval 0.18 to 1.01$)$ for adrenaline alone and 0.52 ( 0.15 to 1.57 ) for combined adrenaline and dexamethasone. Although this provides evidence on the relative efficacy of the different interventions, none of the interventions compared with placebo was statistically significant in this analysis.

Admission rates were also examined up to seven days after the emergency department visit using direct comparisons (fig 2). One large study with low risk of bias showed a statistically significant result for combined adrenaline and dexamethasone, with a 35\% reduction compared with placebo (pooled risk ratio $0.65,95 \%$ confidence interval 0.44 to 0.95 ); number needed to treat 11 (95\% confidence interval 7 to 76$)$. This result was based on a single large trial at low risk of bias; however, the study was factorial and the authors did not anticipate or hypothesise an effect for the combined adrenaline and dexamethasone group a priori. ${ }^{16}$ The strength of evidence for this finding, based on the modified GRADE system, is considered low, as evidence came from only one study with relatively few events. The overall results for steroids compared with placebo and for adrenaline compared with placebo were not statistically significant; however, subgroup analyses examining use of bronchodilators or steroids that followed a protocol showed some important effects (data not shown). Specifically, adrenaline along with steroids that followed a protocol compared with placebo and steroids showed a statistically significant reduction of $33 \%$ (pooled risk ratio $0.67,95 \%$ confidence interval 0.45 to 0.98 ). Also, steroids with use of bronchodilators (adrenaline or salbutamol) that followed a protocol compared with placebo and bronchodilators showed a similar magnitude of effect $(32 \%)$ but did not reach statistical significance (pooled risk ratio $0.68,95 \%$ confidence interval 0.44 to 1.05 ; $\mathrm{P}=0.08)$.

Mixed treatment comparison for admissions up to day 7 identified steroids with bronchodilators (adrenaline or salbutamol) as the interventions with the highest probability of being most effective, although the credibility intervals were wide and do not rule out the possibility of no effect (see web extra appendix D).

Table 2 presents the results from pairwise meta-analysis for change in clinical score. Only nine of the 25 comparisons were statistically significant, and in six of these adrenaline or adrenaline and dexamethasone was the preferred treatment. Compared with placebo, significant benefits were observed for adrenaline at 60 and 120 minutes, combined adrenaline and dexamethasone at 60 minutes, and salbutamol at 60 minutes. Adrenaline showed significant benefits compared with steroids at 60 minutes and salbutamol at 3-10 days. Combined adrenaline and dexamethasone was also superior to salbutamol at 3-10 days. The other two significant results were from one small study at unclear risk of bias showing benefits of salbutamol compared with steroids. The results for other clinical variables were consistent with the findings of admission rates and clinical score or provided little additional information (data available from authors). The incidence of return visits did not differ for any of the five comparisons where data were available (steroid $v$ placebo, steroid $v$ adrenaline, adrenaline $v$ placebo, adrenaline $v$ salbutamol, combined adrenaline and dexamethasone $v$ placebo), although there was only one or two studies within each comparison for this outcome. 
Table $3 \mid$ Results of direct comparisons for change in clinical score among inpatients by comparison

\begin{tabular}{|c|c|c|c|c|}
\hline Comparison & Time point & $\begin{array}{l}\text { No of studies } \\
\text { (No of patients) }\end{array}$ & $\begin{array}{l}\text { Standardised mean } \\
\text { difference }(95 \% \mathrm{Cl})\end{array}$ & $I^{2}(\%)$ \\
\hline \multirow{4}{*}{ Steroid $v$ placebo } & $3-6$ hours & $1(174)$ & $-1.03(-1.87 \text { to }-0.19)^{*}$ & NA \\
\hline & $6-12$ hours & $3(269)$ & $-0.62(-1.00 \text { to }-0.23)^{\star}$ & 10 \\
\hline & $12-24$ hours & $3(264)$ & $-0.28(-0.66$ to 0.09$)$ & 41 \\
\hline & 1-3 days & $4(271)$ & $-0.53(-1.14$ to 0.08$)$ & 70 \\
\hline Adrenaline $v$ placebo & 1 hour & $2(232)$ & $-0.04(-0.49$ to 0.40$)$ & 46 \\
\hline \multirow{2}{*}{ Adrenaline $v$ salbutamol } & 1 hour & $4(248)$ & $-0.79(-1.45$ to -0.13$) \dagger$ & 79 \\
\hline & 2 hours & $1(140)$ & $-0.52(-0.86$ to -0.18$) \dagger$ & NA \\
\hline \multirow{6}{*}{$\begin{array}{l}\text { Salbutamol or terbutaline } \\
v \text { placebo }\end{array}$} & 1 hour & $5(223)$ & $-0.20(-0.76$ to 0.35$)$ & 76 \\
\hline & 2 hours & $2(68)$ & $-0.78(-2.53$ to 0.98$)$ & 91 \\
\hline & $3-6$ hours & $1(89)$ & $-0.20(-0.61$ to 0.22$)$ & 0 \\
\hline & $6-12$ hours & $2(136)$ & $-0.81(-1.21$ to -0.40$) \ddagger$ & 25 \\
\hline & $12-24$ hours & $2(136)$ & $-0.21(-0.62$ to 0.20$)$ & 31 \\
\hline & $1-3$ days & $3(195)$ & $-0.06(-0.47$ to 0.36$)$ & 53 \\
\hline \multirow{5}{*}{ Ipratropium $v$ placebo } & 1 hour & $1(89)$ & $-0.11(-0.53$ to 0.31$)$ & 0 \\
\hline & $3-6$ hours & $1(89)$ & $0.06(-0.39$ to 0.51$)$ & 13 \\
\hline & 6-12 hours & $2(134)$ & $-0.21(-0.80$ to 0.37$)$ & 65 \\
\hline & $12-24$ hours & $3(193)$ & $-0.27(-0.61$ to 0.06$)$ & 27 \\
\hline & $1-3$ days & $3(193)$ & $0.05(-0.38$ to 0.49$)$ & 56 \\
\hline \multirow{5}{*}{ Salbutamol $v$ ipratropium } & 1 hour & $1(43)$ & $-0.22(-0.82$ to 0.38$)$ & NA \\
\hline & 3-6 hours & $1(43)$ & $0.20(-0.40$ to 0.80$)$ & NA \\
\hline & $6-12$ hours & $3(123)$ & $0.16(-0.40$ to 0.72$)$ & 59 \\
\hline & $12-24$ hours & $4(183)$ & $-0.24(-0.54$ to 0.06$)$ & 3 \\
\hline & $1-3$ days & $4(183)$ & $-0.10(-0.39$ to 0.19$)$ & 0 \\
\hline
\end{tabular}

$\mathrm{NA}=$ not applicable.

* Results favour steroid.

†Results favour adrenaline.

$\ddagger$ Results favour salbutamol or terbutaline.

\section{Inpatients}

Figure 5 displays the effect estimates for the primary outcome of length of stay for the different direct comparisons. Only one comparison was statistically significant, showing a shorter length of stay for adrenaline compared with salbutamol (mean difference -0.28 days, $95 \%$ confidence interval -0.46 to -0.09 ). The strength of evidence for this comparison is considered moderate. However, the practical implications of this result need to be considered alongside the finding that adrenaline showed no significant benefit compared with placebo. Furthermore, this finding was sensitive to risk of bias: only one study for this comparison was at low risk of bias and the result was not significant (mean difference

\begin{tabular}{|c|c|c|c|c|c|}
\hline Comparisons (A v B) & $\begin{array}{l}\text { lo of studies/ } \\
\text { lo of patients }\end{array}$ & $\begin{array}{r}\text { Mean di } \\
(95 \%\end{array}$ & $\begin{array}{l}\text { ifference } \\
\% \mathrm{CI})\end{array}$ & $\begin{array}{c}\text { Mean difference } \\
(95 \% \mathrm{Cl})\end{array}$ & $I^{2}(\%)$ \\
\hline Length of stay (days) & & & & & \\
\hline Steroid $v$ placebo & $8 / 633$ & $\longrightarrow$ & & $-0.18(-0.39$ to 0.04$)$ & 16 \\
\hline Adrenaline $v$ placebo & $2 / 292$ & $\longrightarrow$ & - & $-0.35(-0.87$ to 0.17$)$ & 0 \\
\hline Adrenaline $v$ salbutamol & $4 / 261$ & $\rightarrow$ & & $-0.28(-0.46$ to -0.09$)$ & 0 \\
\hline Salbutamol or terbutaline $v$ placebo & $6 / 346$ & & 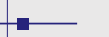 & $0.11(-0.26$ to 0.48$)$ & 0 \\
\hline Ipratropium $v$ placebo & $2 / 148$ & & & $-0.04(-0.53$ to 0.45$)$ & 26 \\
\hline Salbutamol $v$ ipratropium & $3 / 137$ & & $\rightarrow$ & $0.13(-0.33$ to 0.58$)$ & 0 \\
\hline & -1.0 & -0.5 & 0.5 & 1.0 & \\
\hline & Favo & & & rs B & \\
\hline
\end{tabular}

Fig 5 | Results from meta-analysis of direct comparisons for length of stay in inpatients. Only comparisons with quantitative results are shown
-0.07 days, $95 \%$ confidence interval -1.01 to 0.88$)$. The results showed high strength of evidence of no difference for steroid compared with placebo overall. Subgroup analyses showed a significant difference for steroids with use of bronchodilators that followed a protocol (mean difference -0.12 days, -0.23 to -0.00 ); however, the magnitude of effect is not considered clinically important.

Mixed treatment comparison identified combined adrenaline and dexamethasone as the preferred treatment (figs 6 and 7). This finding was driven by one small study at high risk of bias. The confidence interval was wide and did not rule out the potential for no effect. Moreover, the mixed treatment comparison shows that none of the interventions examined show clear efficacy in terms of length of stay among the inpatient population.

In terms of change in clinical score (table 3), few differed statistically significantly (5/23 comparisons). Significant benefits were observed for adrenaline compared with salbutamol at 60 and 120 minutes, steroids compared with placebo at 3-6 and 6-12 hours, and salbutamol or terbutaline compared with placebo at 6-12 hours. The strength of evidence for these findings is limited by risk of bias, inconsistency (or unknown consistency owing to limited numbers of studies within individual comparisons), and lack of precision. The results for other clinical symptoms provided little additional or inconsistent information (data available from authors). Data for return visits and readmissions were available for four comparisons (steroid $v$ placebo, adrenaline $v$ placebo, adrenaline $v$ salbutamol, and salbutamol $v$ placebo). No significant differences were found although only one or two studies were available for each comparison.

\section{Harms}

Sixteen studies provided data on short term adverse effects (see web extra appendix E). No studies examined, or were necessarily designed to examine, long term adverse effects, such as cognitive injury. The types of adverse effects that were most commonly searched for (or reported on) included pallor, vomiting, tremors, hypertension, tachycardia, and infections. In general, the incidence of adverse effects was low and no important differences were observed between groups across the studies.

\section{DISCUSSION}

Previous syntheses provide little conclusive evidence to support the choice of different treatment options in the acute management of bronchiolitis. By examining steroids and bronchodilators in a single systematic review and supplementing the standard meta-analysis with mixed treatment comparisons, this review provides some important directions for clinical practice and future research. Adrenaline seems to be beneficial for short term outcomes among outpatients, including admission rates from the emergency department. Furthermore, adrenaline combined with dexamethasone showed longer term effects, reducing admission 


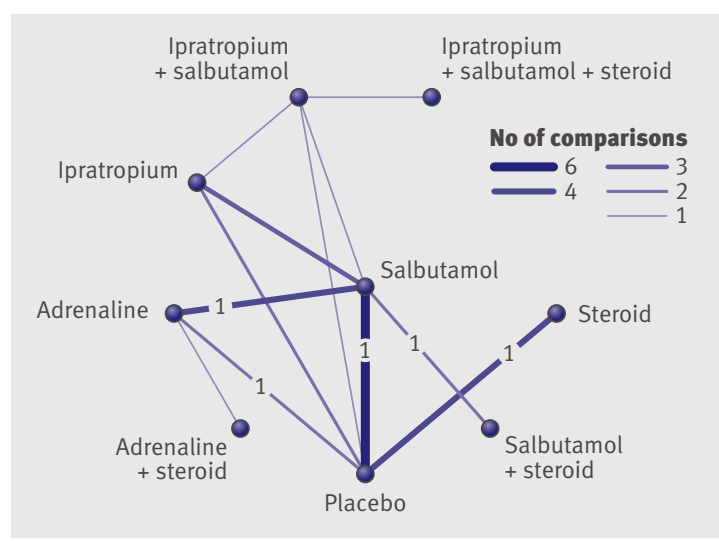

Fig 6 | Comparisons (19 studies) contributing to mixed treatment analysis for length of stay. Numerals within figure are studies at low risk of bias (two in total)

rates up to seven days after the emergency department visit. The strength of evidence for this reduction in admission rates was considered low based on the GRADE system, largely because it came from a single trial; however, recent empirical evidence suggests that reliance on evidence from a single precise trial that has been carried out well is reasonable. ${ }^{32}$ The effectiveness of these interventions is supported by positive benefits in some of the secondary outcome measures, including short term changes in clinical score, with no observed concerns about short term safety. For inpatients, none of the interventions examined showed clear benefits for length of stay. Adrenaline showed some significant improvements for short term changes in clinical score, whereas steroids and salbutamol showed benefits compared with placebo over the longer follow-up periods (3-6 and 6-12 hours).

\section{Interpretation of findings}

The magnitude and timing of observed effects of adrenaline and steroids are supported through their known mechanisms of actions. Adrenaline has been shown to improve short term clinical variables, but its effect on admission rates was unclear, mostly due to underpowered studies. ${ }^{33}$ We did not confirm concerns that the

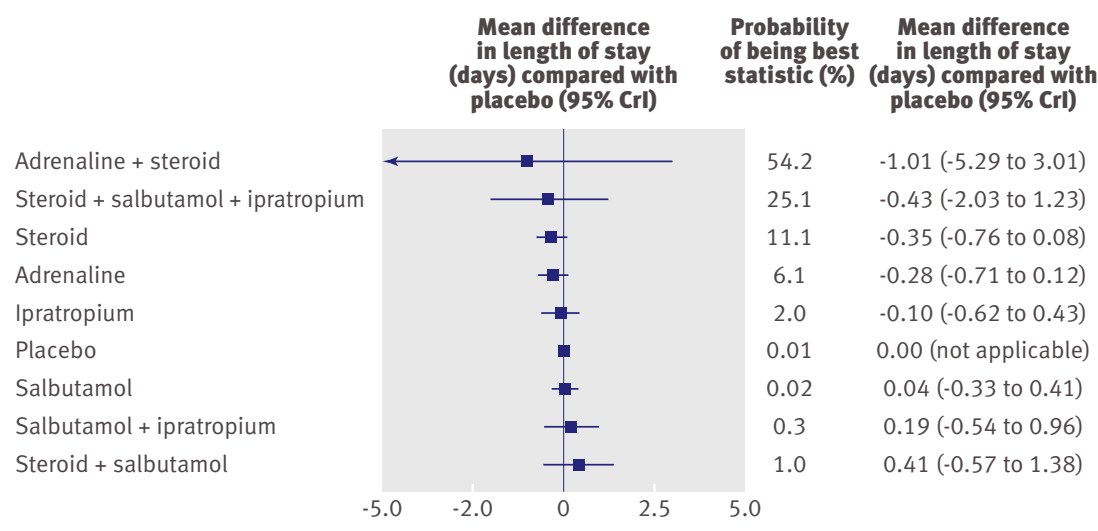

Fig 7| Results of mixed treatment analysis for length of stay, showing probability ranking and probability of being best statistic early benefit shown might result in a later increase in admissions or return visits. ${ }^{34}$ The longstanding claim that the $\alpha$ adrenergic vasoconstricting and oedema reducing activity of adrenaline may confer advantage over $\beta$ adrenergic only drugs was supported by direct and indirect comparisons suggesting some benefit over salbutamol. ${ }^{35}$ Findings also indicate that previous conflicting results on the use of steroids may be partially explained by interaction with bronchodilators. Our analysis clearly excludes a clinically relevant stand alone effect of steroids but shows additive effects when combining a long action steroid such as dexamethasone with use of bronchodilators that follow a protocol. It is recognised that the immune response plays a significant part in the pathogenesis of bronchiolitis ${ }^{36}$ although the biological action of antiinflammatory interventions may be limited ${ }^{37}$ Clinical synergism between steroids and bronchodilators is a major topic in the long term treatment of asthma and chronic obstructive pulmonary disease. ${ }^{38}$ Findings from translational research show a two way molecular interaction between these drugs, including $\beta_{2}$ agonist stimulated steroid mediated gene transcription, and a steroid induced increase in the transcription of the $\beta_{2}$ receptor gene. ${ }^{39}$ Whether these mechanisms are involved in the treatment of acute bronchiolitis, and the contribution of specific types and doses of bronchodilators and steroids, is unknown.

Another outstanding problem is the difference in observed effects between inpatient and outpatient populations. Adrenaline shows benefits for outpatients but not for inpatients. This may be attributable to short term compared with long term response or characteristics of the patients (for example, responders $v$ nonresponders) or illness (for example, timing and severity of infection).

Safety concerns exist about the widespread use of adrenaline and steroids in young children with viral wheezing, particularly with repeated high doses. ${ }^{4041}$ Our results do not suggest any serious or frequent short term expected or unexpected harms from any of the studied interventions in infants with bronchiolitis in the absence of comorbidities. However, our safety analysis is based on randomised trials, which often have limited power to detect important differences owing to the infrequent occurrence of events. Data from trials and observational studies in croup confirm a favourable short term safety profile..$^{42}$ Long term problems raised by the use of steroids in prematurity include effects on adrenal function, cardiovascular responses, somatic and lung growth, and neurodevelopment. ${ }^{43-47}$ Evidence is, however, scarce on the effects for short term use in otherwise healthy term infants, ${ }^{42}$ and none of these were studied in included trials.

\section{Limitations of existing evidence}

Our strength of evidence assessments provide clarity around the limitations of this body of evidence and direction for future research. Two key factors affected the strength of evidence: potential risk of bias in the 


\section{WHAT IS ALREADY KNOWN ON THIS TOPIC}

The management of acute bronchiolitis varies substantially throughout the world, including the use of different bronchodilators and steroids

Systematic reviews have failed to provide convincing evidence to support different treatment options in the acute management of bronchiolitis

\section{WHAT THIS STUDY ADDS}

This systematic review shows a benefit of adrenaline (epinephrine) in reducing day 1 admission rates from the emergency department

Evidence suggests a benefit of combined adrenaline and dexamethasone for reducing admission rates seven days after the emergency department visit

For inpatients, none of the interventions examined showed clear benefits for length of stay; however, limited evidence suggests some benefits on clinical score for adrenaline as well as for steroids and salbutamol compared with placebo

included studies and sparsity of data for many of the outcomes and comparisons, which resulted in imprecise estimates and unknown consistency of estimates across studies. Risk of bias was high due to potential selective outcome reporting, incomplete outcome data, and lack of blinding. Reporting of sequence generation and allocation concealment was often unclear. Sparsity of data was a result of few studies making the same comparisons as well as variability in the choice of outcomes and timing of outcome assessments. The message around consistency and relevance of outcomes is not new for this discipline. ${ }^{4849}$ Further work to define clinically important efficacy and safety outcomes for bronchiolitis is ongoing.

\section{Implications for research}

Future research should focus on areas where there is some suggestion of benefit (significant or close to significant results in direct meta-analysis with a magnitude of effect that is clinically meaningful, or relative superiority in mixed treatment comparisons) but the strength of evidence is moderate or low-that is, future research may change our confidence in the estimate and may change the estimate. Based on this review, adrenaline and combined adrenaline and dexamethasone seem to be emerging as the preferred treatments for outpatients. This review found no clear advantage of steroids or bronchodilators among inpatients. This information should guide the choice of comparators, including their dose and combinations, for future large trials.

\section{Strengths and limitations of the review}

This review has followed current methodological standards for the synthesis of evidence. Moreover, we have incorporated new methods of analysis to simultaneously compare the different interventions and to provide greater clarity around their relative benefits. Limitations of mixed treatment comparisons have been cited, specifically assumptions of sufficient homogeneity to combine data and generalisability to individual patients. ${ }^{20}$ The influence of age, history of wheezing episodes, and wheezing phenotype has led to repeated controversies in this subject, ${ }^{4050}$ and it is not yet clear how best to approach these problems at a trial and systematic review level. We focused on first time wheezing so results could be directly pertinent to infants with typical viral bronchiolitis. We searched extensively for relevant literature and included all studies regardless of language of publication. We are confident that this review represents the most comprehensive synthesis currently available for the two most promising treatments for bronchiolitis, steroids and bronchodilators.

\section{Conclusion}

Uncertainty about the optimal management of bronchiolitis is underscored by evidence showing substantial variation in practice, even within homogenous clinical settings. Current clinical practice guidelines recommend only supportive measures based on the absence of convincing evidence for any other approach. This systematic review shows a benefit of adrenaline for outcomes of most clinical relevance among outpatients. Moreover, adrenaline is shown to be safe and is relatively inexpensive. Some evidence exists for a beneficial synergistic effect of adrenaline and dexamethasone. Further research of this combined treatment is needed among outpatients. For inpatients, none of the interventions examined showed clear benefits for length of stay. Consensus on the most clinically important outcomes and consistency in their application will yield stronger evidence for this important source of morbidity among young children.

We thank the following for their contributions to this project: Annabritt Chisholm (article retrieval), Heather McPhee (data extraction), Nicola Hooton (protocol development, study selection), Özge Tunçalp (Turkish translation), Joy Lee (Korean translation), Paolo Valerio (Dutch translation), and João Franco (Spanish translation). This work is based on two systematic reviews produced for the Cochrane Collaboration on glucocorticoids and adrenaline (epinephrine) for bronchiolitis, respectively.

Contributors: LH, RF, DJ, AP, TK, BV conceived and designed the study. LH, $R F, L B$, and $A M$ screened the literature search results and identified articles for retrieval, reviewed full papers for inclusion, and extracted data for meta-analysis. BV and RF analysed data and carried out multiple treatment comparisons. All authors interpreted the data, critically revised the draft, and gave final approval of the version to be published. $\mathrm{LH}$ is the guarantor for the study.

Funding: This research was supported by the Canadian Institutes of Health Research knowledge synthesis grant programme. The funding agency was not involved with the study design or collection, analysis, and interpretation of the data. RMF is supported by the Calouste Gulbenkian Foundation (Programme for Advanced Medical Education; www. gulbenkian.pt), and Fundação Ciência e Tecnologia.

Competing interests: All authors have completed the Unified Competing Interest form at www.icmje.org/coi_disclosure.pdf (available on request from the corresponding author) and declare that (1) LH, DJ, AP, TPK, and BV have support from the Canadian Institutes for Health Research for the submitted work; (2) none of the authors has relationships with Canadian Institutes for Health Research that might have an interest in the submitted work in the previous 3 years; (3) none of their spouses, partners, or children has financial relationships that may be relevant to the submitted work; and (4) the authors have no non-financial interests that may be relevant to the submitted work.

Ethical approval: Not required.

Data sharing: No additional data available.

1 Wright AL, Taussig LM, Ray CG, Harrison HR, Holberg CJ. The Tucson Children's Respiratory Study: II. Lower respiratory tract illness in the first year of life. Am J Epidemiol 1989;129:1232-46. 
2 Hall CB, Weinberg GA, Iwane MK, Blumkin AK, Edwards KM, Staat MA, et al. The burden of respiratory syncytial virus infection in young children. N Engl J Med 2009;360:588-98.

3 Nair H, Nokes DJ, Gessner BD, Dherani M, Madhi SA, Singleton RJ, et al. Global burden of acute lower respiratory infections due to respiratory syncytial virus in young children: a systematic review and meta-analysis. Lancet 2010;375:1545-55.

4 Viswanathan M, King VJ, Bordley C, Honeycutt AA, Wittenborn J, Jackman AM, et al. Management of bronchiolitis in infants and children. Evid Rep Technol Assess (Summ) 2003;69:1-5.

5 Smyth R, Openshaw P. Bronchiolitis. Lancet 2006;368:312-22.

6 Babl FE, Sheriff N, Neutze J, Borland M, Oakley E. Bronchiolitis management in pediatric emergency departments in Australia and New Zealand: a PREDICT study. Pediatr Emerg Care 2008;24:656-8.

7 Plint AC, Johnson DW, Wiebe N, Bulloch B, Pusic M, Joubert G, et al. Practice variation among pediatric emergency departments in the treatment of bronchiolitis. Acad Emerg Med 2004;11:353-60.

8 Christakis DA, Cowan CA, Garrison MM, Molteni R, Marcuse E, Zerr DM. Variation in inpatients diagnostic testing and management of bronchiolitis. Pediatrics 2005;115:878-84.

9 Barben J, Kuehni CE, Trachsel D, Hammer J: Swill Paediatric Respiratory Research Group. Management of acute bronchiolitis: can evidence based guidelines alter clinical practice? Thorax 2008;63:1103-9.

10 Bialy L, Smith M, Bourke T, Becker L. The Cochrane Library and bronchiolitis: an umbrella review. Evid Based Child Health 2006;1:939-47.

11 American Academy of Pediatrics. Diagnosis and management of bronchiolitis. Pediatrics 2006;118:1774-93.

12 Scottish Intercollegiate Guidelines Network (SIGN). Bronchiolitis in children. A national clinical guideline. Report No 91. SIGN, 2006.

13 Turner T, Wilkinson F, Harris C, Mazza D: Health for Kids Guideline Development Group. Evidence based guideline for the management of bronchiolitis. Aust Fam Physician 2008;37:6-13.

14 Muething S, Schoettker PJ, Gerhardt WE, Atherton HD, Britto MT, Kotagal UR. Decreasing overuse of therapies in the treatment of bronchiolitis by incorporating evidence at the point of care. J Pediatr 2004;144:703-10.

15 Touzet S, Refabert L, Letrilliart L, Ortolan B, Colin C. Impact of consensus development conference guidelines on a primary care of bronchiolitis: are national guidelines being followed? J Eval Clin Pract 2007;13:651-6.

16 Plint AC, Johnson DW, Patel H, Wiebe N, Correll R, Brant R, et al. Epinephrine and dexamethasone in children with bronchiolitis. $N$ Engl J Med 2009;360:2079-89.

17 Corneli HM, Zorc JJ, Mahajan P, Shaw KN, Holubkov R, Reeves SD, et al. A multicenter, randomized, controlled trial of dexamethasone for bronchiolitis. N Engl J Med 2007;357:331-9.

18 Shojania KG, Sampson M, Ansari MT, Doucette S, Moher D. How quickly do systematic reviews go out of date? A survival analysis. Ann Intern Med 2007;147:224-33.

19 Schuh S, Coates AL, Binnie R, Allin T, Goia C, Corey M, et al. Efficacy of oral dexamethasone in outpatients with acute bronchiolitis. J Pediat 2002;140:27-32

20 Ioannidis JPA. Integration of evidence from multiple meta-analyses: a primer on umbrella reviews, treatment networks and multiple treatments meta-analyses. Can Med Assoc J 2009;181:488-93.

21 Caldwell DM, Ades AE, Higgins JPT. Simultaneous comparison of multiple treatments: combining direct and indirect evidence. $B M$ J 2005;331:897-900.

22 Higgins JPT, Green S, eds. The Cochrane handbook for systematic reviews of interventions. The Cochrane Collaboration, 2008.

23 Owens DK, Lohr KN, Atkins D, Treadwell JR, Reston JT, Bass EB, et al. Grading the strength of a body of evidence when comparing medical interventions: Agency for Healthcare Research and Quality and the Effective Health Care Program. J Clin Epidemiol 2010;63:513-23.

24 Schünemann $\mathrm{H}$, Brozek J, Oxman A, eds. GRADE handbook for grading quality of evidence and strength of recommendation. Version 3.2. The GRADE Working Group, 2009.

25 DerSimonian R, Laird N. Meta-analysis in clinical trials. Control Clin Trials 1986;7:177-88.

26 Higgins JP, Thompson SG. Quantifying heterogeneity in a metaanalysis. Stat Med 2002;21:1539-58.
27 Higgins JP, Thompson SG, Deeks JJ, Altman DG. Measuring inconsistency in meta-analyses. BMJ 2003;327:557-60.

28 Lu G, Ades AE. Combination of direct and indirect evidence in mixed treatment comparisons. Stat Med 2004;23:3105-24.

29 Higgins JP, Whitehead A. Borrowing strength from external trials in a meta-analysis. Stat Med 1996;15:2733-49.

30 Smith TC, Spiegelhalter DJ, Thomas A. Bayesian approaches to random-effects meta-analysis: a comparative study. Stat Med 1995;14:2685-99.

31 Dias S, Welton NJ, Caldwell DM, Ades AE. Checking consistency in mixed treatment comparison. Stat Med 2010;29:932-44.

32 Glasziou PP, Shepperd S, Brassey J. Can we rely on the best trial? A comparison of individual trials and systematic reviews. BMCMed Res Methodol 2010;10:23.

33 Hartling L, Wiebe N, Russell K, Patel H, Klassen TP. Epinephrine for bronchiolitis. Cochrane Database Syst Rev 2004;1:CD003123.

34 Scarfone RJ. Controversies in the treatment of bronchiolitis. Curr Opin Pediatr 2005;17:62-6.

35 Wohl MEB, Chernick V. State of the art: bronchiolitis. Am Rev Respir Dis 1978;118:759-81.

36 Openshaw PJ. Antiviral immune responses and lung inflammation after respiratory syncytial virus infection. Proc Am Thorac Soc 2005;2:121-5.

37 Thomas LH, Sharland M, Friedland JS. Steroids fail to down-regulate respiratory syncytial virus-induced IL-8 secretion in infants. Pediatr Res 2002;52:368-72.

38 Giembycz MA, Kaur M, Leigh R, Newton R. A Holy Grail of asthma management: toward understanding how long-acting beta(2)adrenoceptor agonists enhance the clinical efficacy of inhaled corticosteroids. Br J Pharmacol 2008;153:1090-104.

39 Black IL, Oliver BG, Roth M. Molecular mechanisms of combination therapy with inhaled corticosteroids and long-acting beta-agonists. Chest 2009;136:1095-100.

40 Frey $\mathrm{U}$, von Mutius E. The challenge of managing wheezing in infants. N Engl J Med 2009;360:2130-3.

41 Bush A. Practice imperfect-treatment for wheezing in preschoolers. N Engl J Med 2009;360:409-10.

42 Zhang L, Sanguebsche LS. The safety of nebulization with 3 to $5 \mathrm{ml}$ of adrenaline (1:1000) in children: an evidence based review. J Pediatr (Rio J) 2005;81:193-7.

43 Halliday HL, Ehrenkranz RA, Doyle LW. Early ( 8 days) postnata corticosteroids for preventing chronic lung disease in preterm infants. Cochrane Database Syst Rev 2010;1:CD001146.

44 Onland W, De Jaegere AP, Offringa M, van Kaam AH. Effects of higher versus lower dexamethasone doses on pulmonary and neurodevelopmental sequelae in preterm infants at risk for chronic lung disease: a meta-analysis. Pediatrics 2008;122:92-101.

45 Karemaker R, Kavelaars A, Wolbeek M, Tersteeg-Kamperman M, Baerts W, Veen S, et al. Neonatal dexamethasone treatment for chronic lung disease of prematurity alters the hypothalamuspituitary-adrenal axis and immune system activity at school age. Pediatrics 2008;121:e870-8.

46 Wilson-Costello D, Walsh MC, Langer JC, Guillet R, Laptook AR, Stoll BJ, et al. Impact of postnatal corticosteroid use on neurodevelopment at 18 to 22 months' adjusted age: effects of dose, timing, and risk of bronchopulmonary dysplasia in extremely low birth weight infants. Pediatrics 2009;123:e430-7.

47 Karemaker R, Karemaker JM, Kavelaars A, Tersteeg-Kamperman M, Baerts W, Veen S, et al. Effects of neonatal dexamethasone treatment on the cardiovascular stress response of children at school age. Pediatrics 2008;122:978-87.

48 Flores G, Horwitz RI. Efficacy of beta2-agonists in bronchiolitis: a reappraisal and meta-analysis. Pediatrics 1997;100:233-9.

49 King VJ, Viswanathan M, Bordley WC, Jackma AM, Sutton SF, Lohr KN, et al. Pharmacologic treatment of bronchiolitis in infants and children: a systematic review. Arch Pediatr Adolesc Med 2004;158:127-37.

50 Barbi E, Neri E, Ventura A. Nomina sunt consequentia rerum: time for a change in the definition of bronchiolitis? Arch Pediatr Adolesc Med 2004; 158:403.

Accepted: 27 January 2011 